\title{
The Relationship Pattern of Internet Usage Frequency, Generation Z Characteristics, and Teaching Method in the Millennium Era
}

\author{
https://doi.org/10.3991/ijim.v15i18.24555 \\ Thomas Budiman ${ }^{1(\bowtie)}$, Franky Franky² \\ ${ }^{1}$ STMIK Jayakarta, Jakarta Pusat, Indonesia \\ ${ }^{2}$ Universitas Profesor Doktor Moestopo (Beragama), Jakarta Pusat, Indonesia \\ thomas@stmik.jayakarta.ac.id
}

\begin{abstract}
Generation Z students mount challenges to develop teaching methods in the millennium era due to their diverse characteristics from the previous generation as they are proficient in utilizing the internet, less attentive to each other and the environment, prefer immediate things regardless of all complex processes they shall go through. This study aims to seek the relationship pattern between Generation $\mathrm{Z}$ clusters, teaching methods, and internet usage frequency. This study involved 222 junior high school students in Jakarta. The two-step cluster, cross-tabulation, and correspondence analysis were used for data analysis. The method used is correspondence analysis. The findings indicated that internet usage frequency has a significant relationship with Generation $\mathrm{Z}$ clusters and teaching methods. The results concluded that students who use the internet less than five hours prefer the full tutorial method and group assignments, and those who use the internet more than five hours prefer tutorial and field assignments.
\end{abstract}

Keywords - correspondence analysis, generation Z, internet, teaching method

\section{Introduction}

Teaching Generation $\mathrm{Z}$ is a challenge in the millennium era due to their different characteristics from the previous generation. They are experts in using the internet while their teachers are not as skilled as they are. They have less attention to each other and the environment while their teachers want it. Furthermore, they usually like instant things and do not care about the process. This makes them mind teaching methods that require a long process in detail [1]. Close-minded older generation teachers tend to teach them in the old ways requiring long processes with fewer applications. This might make the students disfavor it. As they often communicate with gadgets and social media, they do not like verbal communication. They might prefer a way of teaching that challenges them to seek answers independently or together with groups by searching on the internet. Unfortunately, not all teachers can teach that way. Several older generation teachers remain accustomed to verbal teaching and writing activities. Generation Z 
is usually creative students. They can track many things from the internet while their teachers' methods do not encourage them to develop their skills and preferences.

Not all generation $\mathrm{Z}$ has the characteristics of having low attention, low verbal communication, disregarding the process, and high creativity [2]. Some of them have high attention to others, prefer to communicate verbally, like to learn by paying attention to the process, and do not keep up to date on the internet. This could be due to their frequency of internet usage per day or the condition of their family. This characteristic difference should be the attention of the teachers.

By the Two-Step Cluster method, Generation Z students can be grouped into three clusters [3]. Cluster 1 consists of students with high creativity, high verbal ability, high appreciation of process, and high attention. Cluster 2 comprises students with moderate creativity, low verbal ability, low appreciation to process, and low attention. Cluster 3 takes in students with low creativity, moderate verbal ability, moderate appreciation to the process, and moderate attention.

The use of the internet is believed to affect the formation of the three clusters. The frequency of using the internet per-day could make a difference in how Generation $\mathrm{Z}$ judge their teachers' knowledgeability, characters, attention, desired position, ideal to be a teacher, achievement, teaching methods, and ideal jobs. Recognizing this relation pattern between the characteristics and all other variables influenced by internet usage could better our education management.

This study aims to (1) recognize variables related to the frequency of internet usage, and (2) recognize the pattern of relationship between the characteristics of Generation $\mathrm{Z}$ with variables influenced by internet usage.

\section{Literature review}

This study is conducted to recognize relationship patterns between the characteristics of Generation $\mathrm{Z}$ consisting of creativity, verbal ability, appreciation for processes and attention in learning, and the frequency of internet usages. Perceiving the pattern could lead to the best learning methods [3].

Each generation has special characteristics in its development and growth inseparable from the changing times occurring through scientific, social, political, and cultural. Likewise, the term Generation $\mathrm{Z}$ is close to the significant changes underlying it. They were born in 1995-2010 coincided with the rapid development of information and communication technology. They are inextricable from the development of computer and internet technology, loaded with digital skills and a high frequency of using the internet. On the other hand, they have a low level of attention, low verbal ability, low appreciation for the process, and high creativity.

Attention is a fundamental attitude that is truly possessed by every human being. Humans are social creatures who need other humans to build communication, relationships, and attention.

The development of information and communication technology, more or less, has created a gap in human relations. The internet allows humans to have tens, hundreds, even thousands of friends scattered in distant places. They are interconnected through social media and networks. This condition creates humans more frequently to interact with machines, inanimate objects, than with other humans. 
However, the internet has intervened in verbal communication to be digital. Digital communication reduces attention to other human conditions. Verbal communication bringing warmth, gaze, body language, and voice intonation could be a tool in fostering a sense of attention with other humans. It allows dialogue with other people through technological assistance, despite its limited opportunity. This is the world of Generation Z [4]. Therefore, we need a learning method adaptable to their needs, particularly to their low verbal abilities.

Processes are an essential and fundamental part of every activity and a natural matter through which someone should go. A good process commonly produces good results. No matter how good the input is, when it does not have a good process, the results could be bad. Technology and the internet allow shorter, simpler, and effective processes altering Generation Z's mindset. At a certain speed, it allows the path needed in the process to become short and even tend to be nonexistent. This is the paradigm Generation $\mathrm{Z}$ must have. They often do not care about the process yet more interested in the results. They need a learning method enabling them to gain the results at a glance.

Generation $\mathrm{Z}$ is also characterized by the power of creativity. It allows them to do work in new efficient and innovative ways. Technology and the internet can help them to creatively accomplish the works. They are highly possible to benefit from the presence of internet technology to simplify their works. This should make new learning methods adaptable especially for Generation Z [4,5].

The following provides a conceptual definition and operational definition of the variables involved in this study.

Attention refers to the attitude of Generation $\mathrm{Z}$ to others and the environment. Creativity covers Generation Z's desire to move forward and independently seek knowledge from the internet. Verbal ability is about Generation Z's ability to verbally communicate with others. Appreciation for processes relates to Generation Z's tendency to pay attention to the process of something happening. Satisfaction with the teacher goes into Generation Z satisfaction level with their teachers' teaching methods, characters, and knowledge. Up to date talks about the level of knowledgeability in following technological advances, especially in the use of the internet. The teacher's character delves into teachers' character as discipline, humility, and courtesy. Teacher's attention looks at the teachers' attention level to the students including their direction to the student's bad behavior. These variables are measured by a 1-5 Likert scale.

Job Position has to do with generation Z's desire to have a high job position in the future. Willingness to be a teacher touches on generation Z's desire to become teachers in the future. Both variables are measured by a variable indicator with 5 choices in a questionnaire. Goals refers to generation Z's life goals in their future. This is a categorical variable comprising popularity, wealth, no goals and others. Teaching method tells of their favorite teaching method. This variable is a categorical variable consisting of a full tutorial, tutorial with an individual assignment, tutorial with group assignments, tutorial with field assignments, and independent work without tutorials. Career shows kinds of careers generation $\mathrm{Z}$ would pursue in the future. This variable is a categorical variable including teachers, lecturers, trainers, bankers, finance companies, IT, working with the internet, psychologists, doctors, nurses, clergy, and unemployed. These variables are measured by giving one question in the questionnaire. 


\section{$3 \quad$ Methodology}

This study population consists of Senior High School students in Jakarta. The sample is 222 students filling the questionnaire. The data were analyzed by a Two-Step Cluster, Cross Tabulation, and Correspondence Analysis [6].

\section{$4 \quad$ Results}

A Two-Step Cluster is used to categorize respondents into several clusters which are homogeneous in each cluster and heterogeneous between clusters. From the data, respondents were grouped into 3 groups with the following characteristics in Table 1.

Table 1. Generation $Z$ clustering by characteristic

\begin{tabular}{|l|l|l|l|}
\hline \multicolumn{1}{|c|}{ Description } & \multicolumn{1}{c|}{ Cluster 1 } & \multicolumn{1}{c|}{ Cluster 2 } & \multicolumn{1}{c|}{ Cluster 3 } \\
\hline Creativity & High & Moderate & Low \\
\hline Verbal & High & Low & Moderate \\
\hline Process & High & Low & Moderate \\
\hline Attention & High & Low & Moderate \\
\hline
\end{tabular}

The cross tab is used to determine variables related to internet usage frequency. Table 2 shows the results of data analysis with a significance level of 0.1 .

Table 2. Cross Tabulation of the relationship of Generation $\mathrm{Z}$ characteristic and internet usage frequency

\begin{tabular}{|l|l|}
\hline \multicolumn{1}{|c|}{ Frequencies of Satisfaction to the Teacher } & X \\
\hline Internet Usage & $\sqrt{ }$ \\
\hline Cluster & $\mathrm{X}$ \\
\hline Teachers' Knowledgeability & $\mathrm{X}$ \\
\hline Teachers' Characters & $\mathrm{X}$ \\
\hline Teachers' Attention & $\mathrm{X}$ \\
\hline Job Position & $\mathrm{X}$ \\
\hline Willingness to be A Teacher & $\mathrm{X}$ \\
\hline Goals & $\sqrt{ }$ \\
\hline Teaching Method & $\mathrm{X}$ \\
\hline Careers & \\
\hline
\end{tabular}

The Correspondence Analysis is used to analyze the relationship patterns of internet usage frequency categories (less or more and equal than 5 hours per day), clusters (cluster 1, cluster 2, and cluster 3), and teaching methods (full tutorial, independent work, group work, fieldwork, without tutorial). The data analysis and the result of the joint categorical plot are presented in Figure 1. 


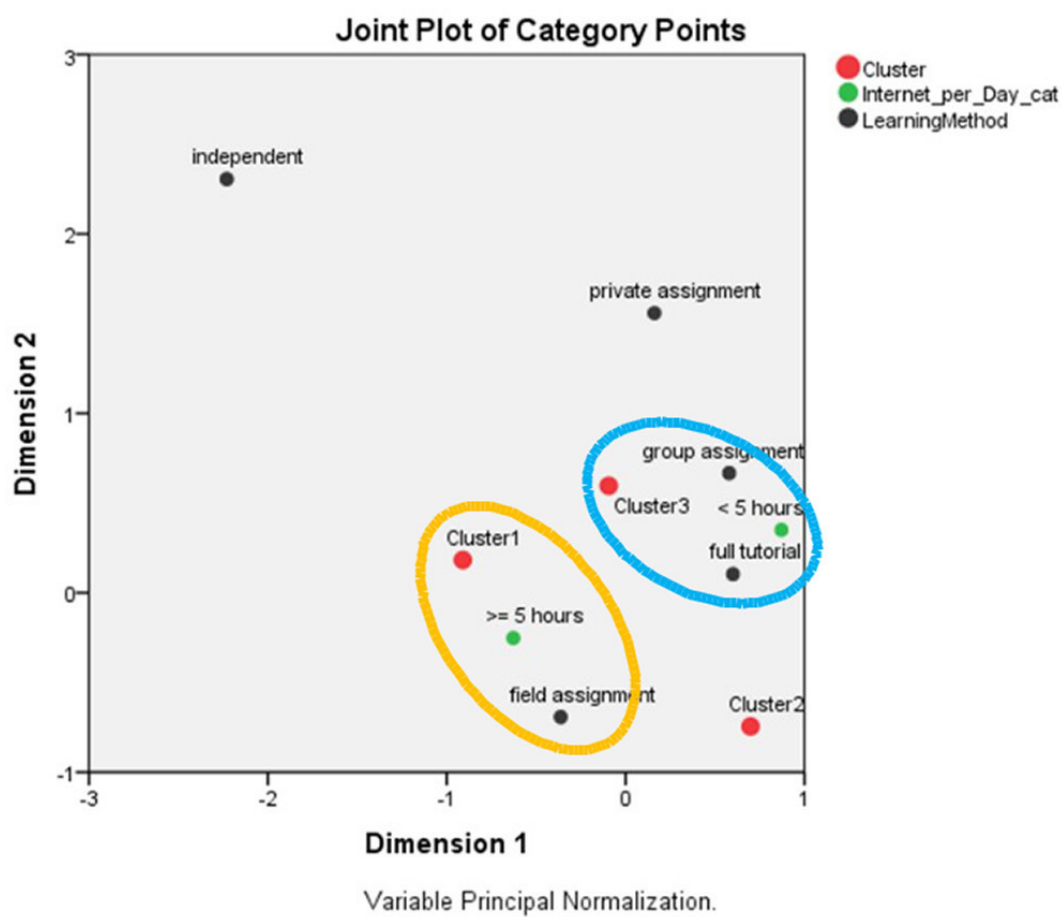

Fig. 1. Cluster plot of internet usage frequencies and teaching methods

Figure 1 shows that generation $\mathrm{Z}$ cluster 1, which has high creativity, high verbal ability, high appreciation to the process, and high attention is related to internet usage more than or equal to 5 hours per day and prefers the method of fieldwork teaching tutorials. Generation Z cluster 3, which has low creativity, moderate verbal ability, moderate appreciation to the process, and moderate attention, shows a relation with a frequency of internet usage less than 5 hours per day and prefers teaching method of full tutorials or tutorials with group assignments. Generation $\mathrm{Z}$ cluster 2 relation with teaching method and internet usage frequency cannot be determined.

\section{Discussion}

Generation $\mathrm{Z}$ who have high creativity, high verbal ability, high appreciation of processes, high attention, and high internet usage frequency, tend to prefer teaching methods with tutorials and field assignments through the internet, certain computer applications, and laboratory practices. Generation $\mathrm{Z}$ with that characteristic combination prefers applicable methods to get certain results despite their concern for the process that must be followed. They keep using verbal communication enabling them to produce scientific group projects. In addition to their attention to others and the environment, their high creativity to use and search for information through the internet allow 
them to be a creative and productive young generation. They need to be well educated and encouraged with proper teaching methods. They need tutorial guidance as well as challenges with opportunities to independently produce great work or in a group.

Generation $\mathrm{Z}$ with low creativity, moderate verbal ability, moderate appreciation for the processes, moderate attention, and low internet usage, favor full tutorial methods or tutorial with group assignments [3]. This could be due to their lack of independence. They need groups to be creative although they cannot verbally communicate and are lack attention for the processes. Those who are interested in the process have a deeper understanding of the roots than those who are quite happy with the results. Generation $\mathrm{Z}$ with this kind of characteristics and inadequate information from the internet will get imperfect results. Thus, they prefer the teaching method of tutorials with group work [7]. This is a practical method for dealing with generation $\mathrm{Z}$ with such characteristics [8]. When they could not find the tutorials, they will independently browse the internet. As stated in [9] Generation $\mathrm{Z}$ is accustomed to using social media for entertainment and for staying current with global events. Group works allow their friends to help them move forward. They can be educated to foster their creativity, practice communicating verbally, and be encouraged to use the internet for good.

These results suggest teachers pay constant attention to educate them in the right way [1]. Possibly, generation $\mathrm{Z}$ students need to be grouped according to their level of creativity, appreciation of processes, and internet usage frequency. Therefore the teaching method could be properly adopted [5], [10], [11], [12], [13], [14].

\section{Conclusion}

The results from this study and published data support the conclusion that: (1) Variables that have a relationship with internet usage frequency are the characteristics of generation $\mathrm{Z}$ and the teaching methods; (2) Generation $\mathrm{Z}$ with high creativity, high verbal ability, high appreciation for processes and high attention relates to internet usage more than or equal to 5 hours per day and prefers the tutorial teaching method with fieldwork. Generation $\mathrm{Z}$ with low creativity, moderate verbal ability, moderate appreciation to the process, and moderate attention are related to internet usage less than 5 hours per day and prefers full tutorial teaching method or tutorial teaching with group assignments

These results come up with suggestions that teachers need to pay attention to the characteristics of the students based on the Generation $\mathrm{Z}$ characteristics, especially their creativity, verbal abilities, attention to others and the environment, their appreciation to process, and frequency of internet usage. Clearly recognizing the characteristics, teachers could develop more appropriate teaching methods. Thus, schools need to use the internet in teaching at schools enabling teachers to teach and give assignments using the internet. Teachers need to teach with recently applicable materials.

\section{$7 \quad$ Acknowledgments}

The researcher expressed his gratitude to 222 respondents who participated in this research. We would like thank to Rianti Setiadi, M.S. (University of Indonesia statistics lecturer) for providing direction and assistance in statistical data analysis. 


\section{References}

[1] Littlejohn, A., Hood, N., Milligan, C., \& Mustain, P. "Learning in MOOCs: Motivations and self-regulated learning in MOOCs", The Internet and Higher Education, 29, pp. 40-48, 2016. https://doi.org/10.1016/j.iheduc.2015.12.003

[2] Dolot, A. "The characteristics of Generation Z Generation Z," E-Mentor, 2(74), pp. 44-50, 2018. https://doi.org/10.15219/em74.1351

[3] Evgeniou, T. “Cluster analysis and segmentation”, 2018. https://inseaddataanalytics.github. io/INSEADAnalytics/CourseSessions/Sessions45/ClusterAnalysisReading.html

[4] Kirschner, P. A., \& De Bruyckere, P. "The myths of the digital native and the multitasker”, Teaching and Teacher Education, 67, pp. 135-142, 2017. https://doi.org/10.1016/j. $\underline{\text { tate. } 2017.06 .001}$

[5] Pennings, H. J. M., Van Tartwijk, J., Wubbels, T., Claessens, L. C. A., Van Der Want, A. C., \& Brekelmans, M. "Real-time teacher-student interactions: A dynamic systems approach", Teaching and Teacher Education, 37, 183-193, 2014. https://doi.org/10.1016/j. $\underline{\text { tate.2013.07.016 }}$

[6] Kroonenberg, P., \& Greenacre, M. "Correspondence analysis", in Encyclopedia of Statistical Sciences (2nd Edition), 2004, pp. 1394-1403. https://doi.org/10.1002/0471667196. ess6018

[7] Gašević, D., Dawson, S., Rogers, T., \& Gasevic, D. "Learning analytics should not promote one size fits all: The effects of instructional conditions in predicting academic success", The Internet and Higher Education, 28, pp. 68-84, 2016. https://doi.org/10.1016/j. iheduc.2015.10.002

[8] Singh, A. P., \& Dangmei, J. "Understanding the Generation Z", South-Asian Journal of Multidisciplinary Studies, 3(3), pp. 1-5, 2016. https://www.researchgate.net/profile/Jianguanglung Dangmei3/publication/305280948 UNDERSTANDING THE GENERATION Z THE FUTURE WORKFORCE/links/5786a11008aef321de2c6f21.pdf

[9] Rissanen, I., Kuusisto, E., Tuominen, M., \& Tirri, K. "In search of a growth mindset pedagogy: A case study of one teacher's classroom practices in a Finnish Elementary School”, Teaching and Teacher Education, 77, pp. 204-213, 2019. https://doi.org/10.1016/j .tate.2018.10.002

[10] Pandey, R., Rao, K. S., Chaurasiya, R., Upadhayay, N., Hongekar, S., Massand, A., Daud, S. Z. B., Kee, D. M. H., Nazir, N. J. B. M., Harun, N. B. M., \& Thevan, P. A. P. S. "Users' perception on their experience with FamPay", Journal of The Community Development in Asia, 4(1), pp. 44-52, 2021. https://doi.org/10.32535/jcda.v4i1.997

[11] Sedova, K., Sedlacek, M., \& Svaricek, R. "Teacher professional development as a means of transforming student classroom talk", Teaching and Teacher Education, 57, pp. 14-25, 2016. https://doi.org/10.1016/j.tate.2016.03.005

[12] Khan, N., Qureshi, M., Mustapha, I., Irum, S., \& Arshad, R. A systematic literature review paper on online medical mobile applications in Malaysia.

[13] Qureshi, M. I, Khan, N., Raza, H., Imran, A., \& Ismail, F. Digital Technologies in Education 4.0. Does it Enhance the Effectiveness of Learning? A Systematic Literature Review. International Journal of Interactive Mobile Technologies, 15(4), 2021. https://doi.org/10.3991/ijim .$v 15 i 04.20291$

[14] Mustapha, I, Van, N. T., Shahverdi, M., Qureshi, M. I, \& Khan, N. Effectiveness of Digital Technology in Education During COVID-19 Pandemic. A Bibliometric Analysis. International Journal of Interactive Mobile Technologies, 15(8), 2021. https://doi.org/10.3991/ijim . $\mathrm{.v15i08.20415}$ 


\section{Authors}

Thomas Budiman is member of the Association of International Business \& Professional Management (AIBPM) since 2018. He is a lecturer and works as the head of the computer engineering study program at Sekolah Tinggi Manajemen Informatika dan Komputer Jayakarta (STMIK Jayakarta) in Indonesia. He has significant competence in programming, analyst, and systems development. The best graduate in post-graduate programs from Universitas Bina Nusantara and get the M.Ti degree.

Dr. Franky is member of the Association of International Business \& Professional Management (AIBPM) since 2018 as well. He is a lecturer and head of the center for research and community service post-graduate program at Universitas Prof. Dr. Moestopo (Beragama) in Indonesia since 2016. The best graduate of doctoral level at Universitas Negeri Jakarta in the education management study program. He is a certified international research reviewer (CIRR) on quantum HRM.

Article submitted 2021-06-04. Resubmitted 2021-07-22. Final acceptance 2021-07-23. Final version published as submitted by the authors. 